\title{
DISPOSICIONES JURISDICCIONALES EN LOS REGLAMENTOS GEMELOS ${ }^{1 *}$
}

\section{IVANA KUNDA}

Catedrática y Responsable del Departamento de Derecho internacional privado en la Facultad de Derecho de la Universidad de Rijeka.

E-mail: $\underline{\text { ikunda@pravri.hr }}$

Agne Limante

Investigadora responsable del Instituto de Derecho del Centro de Ciencias Sociales de Lituania

E-mail: agne.limante@gmail.com

\begin{abstract}
RESUMEN: Se analiza el sistema de normas de competencia judicial regulado en los Reglamentos gemelos sobre el régimen económico matrimonial o de los efectos patrimoniales de las uniones registradas con repercusiones transfronterizas, que tratan de resolver los problemas a los que se enfrentan las parejas para la administración o división de su patrimonio en situaciones de administración o de ruptura como pareja o cuando uno de ellos fallece. Estas reglas son de gran importancia para dar respuesta a cuestiones que afectan a la competencia judicial.
\end{abstract}

Palabras clave: competencia judicial, Reglamentos gemelos, parejas transfronterizas, régimen económico matrimonial, liquidación del patrimonio.

ABSTRACT: This paper analyses the system of rules of jurisdiction of the Twin Regulations on property cross-border relations of spouses or registered partners, who are faced with various questions pertaining in case they find themselves in a situation of dividing their property for the reason of managing it or breaking up as a couple or in case one of them dies. These rules are of huge importance as the first of those questions is that of the court jurisdiction.

Keywords: court jurisdiction, Twin Regulations, cross-border couples, matrimonial property, division of property.

SUMARIO: I. INTRODUCCIÓN. II. LA CONCENTRACIÓN DE COMPETENCIAS COMO PRINCIPIO CLAVE. 2.1. COnCentración en el forum successionis. 2.2. Concentración en el forum divortii. III. JuRisdicción en “otros Casos”.

1 *Traducido por María José Cazorla González, profesora titular de Derecho civil de la Universidad de Almería. 
3.1. Forum prorogatum expressum. 3.2. Forum prorogatum tacitum. 3.3. Las normas por defecto. IV. OTRAS NORMAS DE JURISDICCIÓN. 4.1. El forum alternativum. 4.2. Limitación de los procedimientos. 4.3. Forum subsidiarium. 4.4 Forum necessitates. 4.5. Foro de reconvenciones. 4.6. Foro de medidas provisionales. V. COORDINACIÓN ENTRE LOS PROCEDIMIENTOS DE LOS DISTINTOS ESTADOS MIEMBRos. 5.1. Sustanciación del asunto ante un órgano jurisdiccional. 5.2. Litispendencia. 5.3. Acciones relacionadas. VI. OBSERVACIONES FINALES.

\section{INTRODUCCIÓN}

Los cónyuges o parejas de hecho registradas, que son de distinta nacionalidad, que viven en dos o más Estados como pareja, o que tienen sus bienes situados en dos o más países, se enfrentan a diversas cuestiones relativas al régimen económico matrimonial en caso de que se encuentren en una situación de reparto de sus bienes por motivos de administración o de ruptura como pareja o en caso de que uno de ellos fallezca. ${ }^{2}$ La primera de esas cuestiones es la de la competencia judicial. A menudo, la pareja no está segura en qué Estado puede iniciar el procedimiento y si la división de los bienes puede resolverse junto con otras cuestiones (por ejemplo, el divorcio o la pensión alimenticia). En los Estados miembros que participan en la cooperación reforzada en materia de regímenes matrimoniales y consecuencias patrimoniales de las parejas de hecho, los Reglamentos gemelos proporcionan las respuestas.

El Reglamento UE nº 2016/1103 sobre el régimen económico matrimonial y el Reglamento UE $\mathrm{n}^{\mathrm{o}}$ 2016/1104 sobre las consecuencias patrimoniales de las uniones registradas deben leerse conjuntamente, incluso en lo que respecta a las normas jurisdiccionales que se describen en el capítulo II, artículos 4 a 19 de ambos Reglamentos. Los artículos 4 y 5 establecen las normas jurisdiccionales jerárquicamente dominantes, mientras que el artículo 6 establece las normas jurisdiccionales en "otros casos", complementadas por el artículo 7 sobre una autonomía limitada de las partes para elegir los tribunales competentes de un Estado miembro y el artículo 8 sobre la jurisdicción derivada de la comparecencia del demandado. Otras normas de competencia incluyen la competencia alternativa y subsidiaria (artículos 9 y 10), el forum necessitatis (artículo 11), la reconvención (artículo 12), la limitación de los procedimientos (artículo 13) y las medidas provisionales (artículo 19). Por otra parte, el capítulo II aborda algunas cuestiones procesales distintas de la competencia, como el momento de acudir a un tribunal (artículo 14), el examen de la competencia y la admisibilidad (artículos 15-16), la litispendencia (artículo 17) y las demandas conexas (artículo 18). Estas normas son de aplicación obligatoria, y el tribunal no puede declinar la competencia que le confiere el Reglamento de los gemelos, salvo que una disposición particular a tal efecto lo permita (por ejemplo, los artículos 9 y 13). ${ }^{3}$ Del mismo modo, un tribunal de un Estado miembro al que se le somete un asunto de régimen

2 La noción de "régimen económico matrimonial" en el Derecho internacional privado europeo es amplia y se inspira en sus orígenes de Civil Law. W. Pintens, 'Matrimonial Property Law in Europe' in K. Boele-Woelki, K. Miles and J. Scherpe (eds), The Future of Family Property in Europe, Intersentia, Cambridge/Antwerp/Portland 2011, p. 20. Sobre el mismo concepto en el Reglamento 2016/1103 véanse P. Quinzá Redondo, 'Matrimonial Property Regimes' in I. Viarengo and F.C. Villata (eds.), Planning the Future of Cross Border Families: A Path Through Coordination, Hart Publishing, Oxford 2020, p. 105.

3 P. Franzina, 'Article 13. Limitation of Proceedings' in I. Viarengo and P. Franzina (eds.), The EU Regulations on the Property Regimes of International Couples. A Commentary, Edward Elgar, 2020, p. 132. 
matrimonial sobre el que no es competente en virtud de los Reglamentos gemelos, debe declararse de oficio incompetente con arreglo al artículo 15.

Antes de analizar las normas de competencia, parece conveniente hacer algunas anotaciones estructurales. En primer lugar, salvo las variaciones de los artículos 5 y 6 , las disposiciones sobre competencia del Reglamento de régimen económico matrimonial y del Reglamento sobre las consecuencias patrimoniales de las uniones registradas son equivalentes. Por lo tanto, a lo largo de este capítulo, las referencias al Reglamento de régimen económico matrimonial deben entenderse también como referencias al Reglamento sobre las consecuencias patrimoniales de las uniones registradas, salvo que se indique lo contrario. Del mismo modo, las referencias a los cónyuges o a las cuestiones patrimoniales deben entenderse como referencias a las parejas registradas o a las cuestiones de consecuencias patrimoniales de las parejas registradas, y similares.

En segundo lugar, al igual que otros instrumentos de Derecho internacional privado de la UE, las normas de competencia del Reglamentos gemelos regulan la competencia internacional de los tribunales de los Estados miembros, sin señalar un tribunal concreto dentro de un Estado miembro. Por consiguiente, las normas nacionales sobre la competencia territorial y por razón de la materia en un Estado miembro, determinadas por el Reglamento sobre el patrimonio matrimonial o el Reglamento sobre las consecuencias patrimoniales de las uniones registradas, deben consultarse para determinar el tribunal que se ocupará del caso.

En tercer lugar, la referencia a un "Estado miembro" se limita a los Estados miembros que participan en la cooperación reforzada establecida por los Reglamentos gemelos. En los Estados miembros no participantes, en lugar de los Reglamentos gemelos, los tribunales aplicarán normas nacionales que no entran en el ámbito de aplicación de este capítulo. ${ }^{4}$ Por último, la referencia al término "tribunal" debe entenderse, en la línea del considerando 29 del Reglamento de los gemelos, como una referencia no sólo a los tribunales stricto sensu, sino también a otros organismos competentes o personas encargadas de las funciones judiciales como o en lugar de los tribunales, como los notarios y los profesionales del derecho en algunos Estados miembros. ${ }^{5}$

\section{LA CONCENTRACIÓN DE COMPETENCIAS COMO PRINCIPIO CLAVE}

Como se ha expuesto en el capítulo 2, la UE ha adoptado una serie de reglamentos separados que cubren diferentes aspectos del Derecho internacional privado de la familia, lo que ha dado lugar a un enfoque atomizado: diferentes instrumentos jurídicos regulan la competencia en materia matrimonial, la responsabilidad parental, la sustracción de menores, los alimentos y la sucesión. Cada uno de ellos tiende a establecer sus propias normas jurisdiccionales con diversos motivos de competencia. Además, algunas cues-

$4 \quad$ Véase el capítulo 3 de este volumen.

5 En Francia se confía a los notarios, mientras que en Italia estas decisiones las toman los registros civiles y los abogados. Véase L. Rugerri, 'Registered Partnerships and Property Consequences. Jurisdiction', in M.J. Cazorla González, M. Giobbi, J. Kramberger Škerl, L. Ruggeri and S. Winkler (eds.), Property Relations of Cross Border Couples in the European Union, Edizioni Scientifiche Italiane, Napoli 2020, p. 59. 
tiones de derecho de familia no están contempladas en los instrumentos jurídicos unificados de la UE, como la competencia en materia de estatuto personal o la terminación de las uniones registradas. El empleo de una variedad de instrumentos nacionales y de la UE se complica aún más por el hecho de que hay pocas referencias cruzadas entre esos instrumentos y, en particular, las normas jurisdiccionales. ${ }^{6}$ Los Reglamentos gemelos se distinguen en este sentido porque se apoyan parcialmente en las normas jurisdiccionales unificadas de la UE en materia de sucesiones ${ }^{7}$ y asuntos matrimoniales ${ }^{8}$ y en las normas jurisdiccionales nacionales en materia de disolución o anulación de la unión registrada. Los Reglamentos gemelos, que aparecen más tarde en la línea de los reglamentos de Derecho internacional privado de la $\mathrm{UE},{ }^{9}$ reconocen las ventajas de la interconexión entre los instrumentos de Derecho de familia de la UE, en particular de la concentración de la jurisdicción. ${ }^{10}$ Los artículos 4 y 5 son obligatorios en sus respectivos ámbitos de aplicación y ocupan un lugar primordial en la arquitectura jurisdiccional de los Reglamentos gemelos, por encima de las demás normas jurisdiccionales. En consecuencia, los órganos jurisdiccionales de cualquier Estado miembro distinto de los competentes en virtud de los artículos 4 o 5, según el caso, tienen que declararse de oficio, de conformidad con el artículo 15, incompetentes. ${ }^{11}$

\subsection{Concentración en el forum successionis}

El artículo 4 del Reglamento de régimen económico matrimonial concentra la competencia en materia de régimen económico matrimonial en caso de fallecimiento de uno de los cónyuges ante los órganos jurisdiccionales de los Estados miembros en los que se inicie el procedimiento de sucesión. Prevé que los tribunales de un Estado miembro que conozcan de la sucesión de un cónyuge en virtud del Reglamento de sucesiones (forum successionis) sean también competentes para pronunciarse sobre las cuestiones de régimen económico matrimonial que se planteen en relación con ese caso de sucesión. Además de garantizar la economía y la eficacia de los procedimientos, esta concentración también pretende evitar posibles dificultades o resultados incoherentes derivados

6 Se prevé la remisión de un instrumento de la UE a otro entre los alimentos y la responsabilidad parental, mientras que la remisión de un instrumento de la UE a una ley nacional se hace entre los alimentos y el estatuto personal. Véanse las letras c) y d) del artículo 3 del Reglamento sobre alimentos. La referencia dentro de un instrumento vincula (mediante la prórroga de la competencia) la competencia en materia de responsabilidad parental a la materia matrimonial en el artículo 12(1) del Reglamento Bruselas II bis.

$7 \quad$ Véase el Reglamento de sucesiones.

8 Véase el Reglamento Bruselas II bis, que será sustituido a partir del 1 de agosto de 2022 por el Reglamento Bruselas II ter.

9 Las normas de Derecho internacional privado sobre los regímenes económicos matrimoniales ya se planificaron en The Hague Programme: strengthening freedom, security and justice in the European Union, OJ C 53, 3.3.2005, pp. 1-14, especially p. 13. Véase C. Honorati, 'Verso una competenza della Comunità europea in materia di diritto di famiglia?', in S. Bariatti (ed.), La famiglia nel diritto internazionale privato communitario, Guiffrè editore, Milano 2007, p. 21.

10 Véase Considerando 32 del Reglamento sobre el régimen económico matrimonial. Véase también A. Limante and N. Pogorelčnik Vogrinc, 'Party Autonomy in the Context of Jurisdictional and Choice of Law Rules of Matrimonial Property Regulation' (2020) 13 Baltic Journal of Law \& Politics 135, 142.

11 I. Kunda, 'Novi međunarodnoprivatnopravni okvir imovine bračnih i registriranih partnera u Europskoj uniji: polje primjene i nadležnost' ['Nuevo marco de Derecho internacional privado para el régimen económico matrimonial y de la pareja registrada en la Unión Europea: ámbito de aplicación y competencia'] (2019) Hrvatska pravna revija [Revista de la ley croata] 27, 31. 
de la interconexión entre las cuestiones de los regímenes sucesorio y matrimonial. ${ }^{12}$ Esta solución, sin duda, es puramente lógica, ya que, según las leyes de muchos países, la liquidación del régimen matrimonial precede a la decisión sobre la sucesión, y la sucesión sólo abarca los bienes del fallecido y no del cónyuge superviviente. Así, la concentración de la competencia tiene en cuenta los estrechos vínculos entre las cuestiones de sucesión y de patrimonio matrimonial que permiten una gestión razonable de los dos procedimientos. No obstante, se limita a la competencia internacional de un Estado miembro concreto, mientras que la aplicación de sus normas nacionales sobre la competencia territorial y material intraestatal puede dar lugar a que el procedimiento de sucesión y el procedimiento matrimonial sean tramitados por separado por dos órganos diferentes en un Estado miembro. ${ }^{13}$ La ventaja de la concentración no se pierde, ya que la coherencia y la coordinación se mantienen seguramente en un grado mucho mayor dentro de un único sistema jurídico, que entre dos diferentes.

La norma jurisdiccional del artículo 4 es obligatoria, no tolera excepciones y no puede ser derogada por la voluntad de las partes, como se ha explicado anteriormente. Los requisitos que desencadenan su aplicación son sencillos, triples y acumulativos: (i) que el tribunal de un Estado miembro conozca del caso de sucesión relativo a un cónyuge fallecido, (ii) que la competencia de ese tribunal se establezca en virtud del Reglamento de sucesiones, y (iii) que las cuestiones del régimen económico matrimonial estén relacionadas con ese caso de sucesión. ${ }^{14}$ Los requisitos se han interpretado de forma amplia en la literatura, en particular el requisito de conexidad, que debe abarcar no sólo los casos de bienes matrimoniales en los que se deben resolver cuestiones de carácter preliminar al procedimiento de sucesión, sino también cuestiones como la obtención de pruebas que podrían contribuir a la economía procesal. ${ }^{15}$ Corresponde al tribunal al que se le ha encomendado la tarea de evaluar la conexión a la luz del artículo $4 .{ }^{16}$

Cuando un tribunal de un Estado miembro conoce de un caso de sucesión, los asuntos matrimoniales siguen atraídos a la misma jurisdicción por la fuerza de la conexión accesoria. En virtud del principio de perpetuatio jurisdictionis, la concentración de la competencia se mantiene incluso si el asunto de la sucesión finaliza tras el inicio del asunto matrimonial, porque se ha decidido definitivamente, se ha resuelto o no. ${ }^{17}$ Por el contrario, si el tribunal se ocupa del asunto matrimonial después de que el asunto de la

12 A. Bonomi, 'Article 4. Jurisdiction in the Event of the Death of One of the Spouses [Partners]' in I. Viarengo and P. Franzina (eds.), supra n. 2, pp. 52-53.

13 P. Franzina, 'Jurisdiction in Matters related to Property Regimes under EU Private International Law', (2017/2018) 19 Yearbook of Private International Law 159, 169. Véase una interpretacion crítica en P. Mankowski, 'Internationale Zuständigkeit nach EuGüVO und EuPartVO' in A. Dutta and J. Weber (eds.), Die Europäischen Güterrechtsverordnungen, C. H. Beck, München 2017, p. 14.

14 Comparar A. Bonomi, 'Article 4. Jurisdiction in the event of the death of one of the spouses [partners]' in I. Viarengo and P. Franzina (eds.), supra n. 2, p. 56, que aceptando el requisito previsto en la letra b) afirma que „no se desprende totalmente del texto“. En este caso, se alega que el texto "un tribunal de un Estado miembro es competente en materia de sucesión de un cónyuge en virtud del Reglamento (UE) n n 650/2012” es claro y no deja lugar a otra interpretación que la de que la condición prevista en la letra b) es directa.

15 P. Franzina, supra n. 12, 159, 171.

16 R. Frimston, 'Article 4: Jurisdiction in the Event of Death of One of the Spouses' in U. Bergquist, D. Damascelli, R. Frimston, P. Lagarde and B. Reinhartz, The EU Regulations on Matrimonial and Patrimonial Property, Oxford University Press, Oxford 2019, p. 49.

17 P. Franzina, supra n. 12, 159, 166; A. Bonomi, 'Article 4. Jurisdiction in the event of the death of one of the spouses [partners]' in I. Viarengo and P. Franzina (eds.), supra n. 2, p. 55. 
sucesión ya haya finalizado, el artículo 4 no será aplicable y en su lugar deberán aplicarse los artículos 6 y siguientes.

La aplicación del artículo 4 significa que la competencia en materia matrimonial depende directamente de los criterios de competencia establecidos en el Reglamento de sucesiones. A diferencia del artículo 5, como se verá más adelante, en el artículo 4 no se hace ninguna distinción entre los criterios de competencia del Reglamento de sucesiones. ${ }^{18}$ La norma general de competencia del artículo 4 establece la competencia de los tribunales del Estado miembro en el que el fallecido tuviera su residencia habitual en el momento del fallecimiento, lo que ha sido objeto de una reciente interpretación por parte del TJUE en el asunto E.E. ${ }^{19}$

E.E. es un ciudadano lituano cuya madre se casó con K.-D.E., de nacionalidad alemana. Junto con su madre, E.E., aún menor de edad, se trasladó a vivir a Alemania. En 2013, la madre de E.E. redactó un testamento en la notaría de Garliava (Lituania) y nombró a su hijo E.E. como único heredero de todo su patrimonio. Tras el fallecimiento de su madre, ocurrido en Alemania, E.E. solicitó a la notaría de Kaunas (Lituania) que abriera la sucesión y emitiera un certificado de derechos sucesorios en 2017. El notario se negó a hacerlo convencido de que la residencia habitual de la difunta, en el momento de su muerte, estaba en Alemania, a pesar de que la madre de E.E. era una nacional lituana que nunca había roto sus vínculos con su patria. Aunque el Tribunal Supremo de Lituania no preguntó directamente por la residencia habitual del fallecido (en el momento de la muerte), el TJUE proporcionó algunas directrices de forma incidental. El TJUE subrayó que el Reglamento de sucesiones se basa en el concepto de una única residencia habitual del fallecido, lo que excluye la posibilidad de considerar a una persona como residente habitual en varios Estados. ${ }^{20}$ Remitiéndose a los considerandos 23 y 24 del Reglamento, el TJUE fijó los criterios para establecer la residencia habitual del difunto. La autoridad que tramita la sucesión debe realizar una evaluación global de las circunstancias de la vida del difunto durante los años anteriores a su muerte y en el momento de su fallecimiento, teniendo en cuenta todos los elementos de hecho pertinentes, en particular la duración y la regularidad de la presencia del difunto en el Estado de que se trate, así como las condiciones y los motivos de dicha presencia. A continuación, la autoridad debe comprobar cuál era el centro de intereses de la familia del fallecido y su vida social. Donde esto siga siendo insuficiente para establecer la residencia habitual del fallecido, deberá tenerse en cuenta el conjunto de criterios secundarios: la nacionalidad y la ubicación de los bienes. ${ }^{21}$

Como señala Bonomi, cuando la jurisdicción en un caso de sucesión se basa en la residencia habitual del fallecido en virtud del artículo 4 del Reglamento de sucesiones, la concentración de la jurisdicción en el caso de los bienes matrimoniales dentro del mismo

18 P. Mankowski, 'Internationale Zuständigkeit nach EuGüVO und EuPartVO' in A. Dutta and J. Weber (eds.), supra n. 12, p. 15 .

19 Asunto C-80/19, E.E., EU:C:2020:569.

20 Asunto C-80/19, E.E., EU:C:2020:569, paragrafo 40.

21 Véase un studio más detallado sobre este asunto en A. Limantè, 'The E.E. Decision (C-80/19) Sheds Light on Notaries Acting as 'Courts' and on a Few Other Notions within the Context of the Succession Regulation' (2021) 6 European Papers 45-55. 
Estado miembro es previsible y suele estar cerca del cónyuge superviviente. ${ }^{22}$ También existe una proximidad necesaria entre los asuntos matrimoniales y el tribunal que conoce de los asuntos sucesorios, por ejemplo, a efectos de la obtención de pruebas. El vínculo es, según Bonomi, más débil cuando la competencia en materia de sucesiones se basa en otros motivos, por ejemplo, el artículo 10 del Reglamento de sucesiones, que establece la competencia subsidiaria y enumera la nacionalidad, la residencia habitual anterior y la ubicación de los bienes como motivos de competencia. ${ }^{23}$ Además, el artículo 5 del Reglamento sobre sucesiones permite a las partes interesadas elegir el tribunal del Estado miembro cuya ley fue elegida por el difunto para regir su sucesión en virtud del artículo 22 del Reglamento sobre sucesiones. Esto ha sido caracterizado por algunos como una "llamativa influencia de los herederos" sobre la jurisdicción que se extiende a los asuntos matrimoniales por poner al cónyuge superviviente en una posición imprevista y poco práctica. ${ }^{24}$ No parece ser una preocupación real al menos en aquellas circunstancias en las que uno de los herederos es el cónyuge superviviente. A saber, el acuerdo de prórroga en virtud del artículo 5 del Reglamento de sucesiones debe ser celebrado por las partes interesadas, lo que significa que todas las partes que tienen un interés en la sucesión son partes necesarias en el acuerdo de prórroga. En el caso de que una de ellas no sea parte del acuerdo, como el cónyuge supérstite, el tribunal elegido mantendrá la competencia sólo si dicha parte externa al acuerdo comparece sin poner a prueba la competencia del tribunal de conformidad con el artículo 9 del Reglamento de sucesiones. ${ }^{25}$

Conviene subrayar que la norma de concentración establecida en el artículo 4 sólo se aplica cuando el órgano jurisdiccional que conoce del asunto sucesorio está situado en un Estado miembro que participa tanto en el Reglamento sobre los bienes matrimoniales o en el Reglamento sobre los efectos patrimoniales de las uniones registradas, según el caso, como en el Reglamento sobre sucesiones. Aunque todos los Estados miembros que están vinculados por el Reglamento sobre doble grado de parentesco también lo están por el Reglamento sobre sucesiones, el número de países vinculados por el Reglamento sobre sucesiones (todos los Estados miembros, excepto Dinamarca e Irlanda) es mayor que el de los vinculados por el Reglamento sobre doble grado de parentesco (18 Estados miembros). Si el tribunal de, por ejemplo, Lituania, Polonia o Hungría, que no están vinculados por el Reglamento del Mellizo, recibe el caso de la sucesión, existe un conflicto potencial de jurisdicción para los asuntos matrimoniales entre aquellos Estados miembros en los que dicha jurisdicción puede establecerse en virtud de las normas nacionales y otros Estados miembros en los que dicha jurisdicción puede establecerse en virtud del artículo 6 del Reglamento sobre el régimen económico matrimonial. ${ }^{26}$

22 A. Bonomi, 'The Regulation on Matrimonial Property and Its Operation in Succession Cases - Its Interaction with the Succession Regulation and Its Impact on Non-participating Member States' (2020) 26 Problemy Prawa Prywatnego Międzynarodowego [Issues in Private International Law] 71, 81 <https://doi.org/10.31261/ PPPM.2020.26.07> accessed 07.04.2021.

23 A. Bonomi, 'Article 4. Jurisdiction in the Event of the Death of One of the Spouses [Partners]' in I. Viarengo and P. Franzina (eds.), supra n. 2, p. 64.

24 J. Gray and P. Quinzá Redondo, The Coordination of Jurisdiction and Applicable Law, in J.-S. Bergé, S. Francq and M. Gardeñes Santiago (eds.), Boundaries of European Private International Law, Bruylant, Bruxelles 2015, p. 642.

25 I. Kunda and D. Vrbljanac, 'Choice of Court and Applicable Law under Regulation (EU) 650/2012' in M.J. Cazorla González and L. Ruggeri (eds.), Guidelines for Practitioners in Cross-Border Family Property and Succession Law, Dykinson, Madrid 2020, p. 51.

26 Véase A. Bonomi, supra n. 21, 71, 85. 


\subsection{Concentración en el forum divortii}

A semejanza del artículo 4, el artículo 5 de los Reglamentos gemelos tiene por objeto concentrar la competencia en un Estado miembro, el del fórum divortii. Establece que los órganos jurisdiccionales de los Estados miembros que conozcan de una demanda de divorcio, separación judicial o nulidad matrimonial en virtud del Reglamento Bruselas II bis (que será sustituido por el Reglamento Bruselas II ter) también serán competentes para resolver las cuestiones patrimoniales que se planteen en relación con dicha demanda. Como las cuestiones matrimoniales hoy en día suelen surgir como consecuencia de la disolución del matrimonio, el artículo 5 será probablemente la norma jurisdiccional más utilizada en el Reglamento sobre los gemelos.

A semejanza del artículo 4, los requisitos que desencadenan la aplicación del artículo 5 son acumulativos: a) el órgano jurisdiccional de un Estado miembro es competente para pronunciarse sobre la demanda en materia matrimonial (divorcio, separación judicial o nulidad del matrimonio), b) la competencia de dicho órgano jurisdiccional se establece de conformidad con el Reglamento Bruselas II bis, y c) las materias del régimen económico matrimonial están relacionadas con dicha demanda en materia matrimonial. Los comentarios anteriores relativos a los requisitos del artículo 4 son aplicables mutatis mutandis también al artículo 5.

Sin embargo, el artículo 5 del Reglamento de régimen económico matrimonial tiene una característica adicional: prevé dos vías diferentes para la concentración de la jurisdicción. En algunos casos, la concentración de la jurisdicción es automática (sin reservas), en otros, se requiere el consentimiento de los cónyuges en cuanto a la concentración de la jurisdicción. ${ }^{27}$ La necesidad del consentimiento depende del criterio de competencia del Reglamento Bruselas II bis invocado en el caso de divorcio. La prórroga automática de la competencia está prevista para los casos en que la competencia para el divorcio se basa en los cuatro primeros criterios del artículo 3, apartado 1, letra a), del Reglamento Bruselas II bis, también denominados motivos de competencia "fuertes": 28 la actual o última residencia habitual común de los cónyuges, la residencia habitual del demandado y la residencia habitual de cualquiera de ellos en caso de solicitud conjunta.

Dos nacionales italianos están casados y viven en España. Si uno de ellos inicia el procedimiento de divorcio en España, los tribunales españoles serán competentes para resolver el caso de divorcio de conformidad con el artículo 3, apartado 1, letra a), primer guión, del Reglamento Bruselas II bis. De acuerdo con el artículo 5 del Reglamento sobre el régimen económico matrimonial o el Reglamento, los tribunales españoles serán automáticamente competentes para decidir también sobre las cuestiones relativas al régimen económico matrimonial de los cónyuges.

27 A diferencia del artículo 5 del Reglamento sobre el régimen económico matrimonial, en el caso de las uniones registradas de conformidad con el apartado 2 del artículo 5 del Reglamento sobre las consecuencias patrimoniales de las uniones registradas, siempre es necesario el acuerdo entre los miembros de la pareja para la concentración de la competencia en el forum dissolutionis. Esto se justifica por el hecho de que, como la competencia en los procedimientos de disolución de las uniones registradas se basa en las normas nacionales de Derecho internacional privado (el Reglamento Bruselas II bis sólo se aplica a los matrimonios) y, por tanto, puede diferir entre los Estados miembros.

28 P. Franzina, supra n. 12, 159, 172. 
Cuando la competencia para el divorcio se basa en los "motivos de competencia débil" 29 del artículo 3, apartado 1, letra a), guiones quinto y sexto, del Reglamento Bruselas II bis, que permiten a uno de los cónyuges elegir la jurisdicción más cercana a él (el solicitante ha residido en un Estado miembro durante al menos un año inmediatamente antes de presentar la solicitud o seis meses en el caso de un Estado miembro de su nacionalidad) y sufren un "déficit de legitimidad", ${ }^{30}$ los cónyuges tienen que estar de acuerdo en concentrar la competencia para los bienes matrimoniales en el Estado miembro respectivo. Al exigir el consentimiento de los cónyuges en estos casos, el Reglamento sobre el régimen económico matrimonial pretende garantizar la equidad, de modo que la elección de la jurisdicción más cercana para el divorcio no se traduzca en la elección de la jurisdicción para los bienes matrimoniales. ${ }^{31}$ En otras palabras, es importante limitar los beneficios de la búsqueda del foro más ventajoso, resultante del carácter alternativo ${ }^{32} \mathrm{de}$ los criterios de competencia del artículo 3 del Reglamento Bruselas II bis. ${ }^{33}$ El acuerdo del cónyuge para concentrar la jurisdicción también se requiere en los casos en que se invoca la norma jurisdiccional para la conversión de la separación legal en divorcio del artículo 5 o la jurisdicción residual del artículo 7 del Reglamento Bruselas II bis. Si no se alcanza dicho acuerdo, se aplicará el artículo 6 del Reglamento sobre el régimen económico matrimonial.

Un marido croata y una mujer italiana viven en Croacia. Al cabo de unos años, la mujer recibe una oferta de trabajo en Bruselas y se traslada allí. El marido se queda en Croacia. Después de un año en Bruselas, la esposa solicita el divorcio allí. En virtud del artículo 3, apartado 1, letra a), quinto guión, del Reglamento Bruselas II bis, los tribunales belgas serían competentes para el divorcio. Sin embargo, las cuestiones relativas a los bienes matrimoniales sólo serán competencia de los tribunales belgas si el marido acepta dicha concentración de conformidad con el artículo 5, apartado 2, letra a), del Reglamento sobre los bienes matrimoniales. A falta de acuerdo del marido sobre la concentración de competencias, los tribunales belgas decidirán sobre la demanda de divorcio, mientras que el tribunal competente para decidir sobre la disolución del patrimonio matrimonial se determinará con referencia al artículo 6.

Según el artículo 5, apartado 3, del Reglamento sobre el régimen económico matrimonial, si el acuerdo sobre la concentración de la competencia para los bienes matrimoniales con la competencia para el divorcio en virtud del Reglamento Bruselas II bis se celebra antes de que el tribunal se pronuncie sobre los bienes matrimoniales, el acuerdo tiene que cumplir con el artículo 7, apartado 2, del Reglamento sobre el régimen económico matrimonial. Lo mismo se establece en el artículo 5, apartado 2, del Reglamento sobre las consecuencias patrimoniales de las uniones registradas, con referencia a su artículo 7. Según Frimston, el concepto de "acuerdo" debe interpretarse de

29 Ibid., 159, 172.

30 P. Mankowski, 'Internationale Zuständigkeit nach EuGüVO und EuPartVO' in A. Dutta and J. Weber (eds.), supra n. 12, p. 18.

31 A. Limantė and N. Pogorelčnik Vogrinc, supra n. 9, 135, 145.

32 See Asunto C-168/08, Hadadi, EU:C:2009:474, paragrafo 48

33 W. Pintens and J.M. Scherpe, 'Matrimonial Property', in J. Basedow et al. (eds.), Encyclopedia of Private International Law, Vol. 2, Edward Elgar, Cheltenham 2017, p. 1239. 
forma autónoma como una declaración vinculante de las partes que atribuye la competencia sobre los bienes matrimoniales a los tribunales del Estado miembro competente para resolver la solicitud de divorcio u otra cuestión. ${ }^{34}$ El acuerdo puede celebrarse en cualquier momento antes de que se acuda al tribunal, pero también es posible que las partes acepten que el tribunal que conoce de la disolución del matrimonio o de la pareja de hecho sea competente para pronunciarse sobre la cuestión patrimonial expresando dicho acuerdo cuando el caso ya está pendiente ante el tribunal. En este contexto, Viarengo sugiere que, a falta de cualquier indicación en contrario en el Reglamento de los gemelos, sería razonable suponer que permite también la aceptación tácita de la competencia del tribunal al que se acude, de acuerdo con las normas pertinentes (pro-cedimiento) vigentes en el Estado miembro del foro. ${ }^{35}$ Aunque la concentración de varios procedimientos conexos ante los tribunales de un solo Estado miembro es un objetivo importante de los Reglamentos gemelos, ${ }^{36}$ la conclusión anterior sobre la aceptación tácita es difícil de conciliar tanto con el sistema general de las disposiciones del Reglamento sobre los gemelos que funcionan como un conjunto de normas autosuficientes (excepto cuando se prevé explícitamente la competencia residual) como con la redacción específica del artículo 5 que remite explícitamente al artículo 7, pero no al artículo 8 sobre la prorogatio tacita. ${ }^{37}$ De ello se deriva que, en aras de la seguridad jurídica y de la previsibilidad y el apoyo a las decisiones de la parte informada, es necesario un acuerdo explícito, cuando se requiera, en virtud del artículo 5 y no puede sustituirse por la presentación tácita y mucho menos en virtud de las normas procesales nacionales. Con respecto a los requisitos relativos a la forma de un acuerdo, se remite al subcapítulo que trata del artículo $7 .{ }^{38}$

\section{JURISDICCIÓN EN 'OTROS CASOS'}

Los Reglamentos gemelos otorgan prioridad a la unidad del órgano jurisdiccional para los casos relacionados, así como a la cooperación judicial en asuntos civiles a través de diferentes instrumentos jurídicos. Sin embargo, la concentración de la competencia judicial no puede lograrse en ciertas situaciones en las que la aplicación de los artículos 4 y 5 falla. La competencia en tales situaciones se establece en virtud de las normas de competencia por defecto del artículo 6 si las partes no eligen un foro en virtud del artículo 7 y no se produce una sumisión tácita a la competencia en virtud del artículo 8.

34 R. Frimston, 'Article 5: Jurisdiction in Case of Divorce, Legal Separation or Marriage Annulment' in U. Bergquist, D. Damascelli, R. Frimston, P. Lagarde and B. Reinhartz, supra n. 15, p. 57.

35 I. Viarengo, 'Article 5 Jurisdiction in Cases of Divorce, Legal Separation or Marriage Annulment [in Cases of Dissolution or Annulment]' in I. Viarengo and P. Franzina (eds.), supra n. 2, p. 76.

36 Véase el considerando 32 de los Reglamentos gemelos.

37 Lo mismo ocurre con la disposición paralela del artículo 4, apartado 2, de Proposal for a Council Regulation on jurisdiction, applicable law and the recognition and enforcement of decisions in matters of matrimonial property regimes, COM/2011/0126 final - CNS 2011/0059, que dice: 'Such an agreement may be concluded at any time, even during the proceedings. If it is concluded before the proceedings, it must be drawn up in writing and dated and signed by both parties.' Estos requisitos de forma implican necesariamente un acuerdo explícito, que no se modificaron en la versión final de las disposiciones, sino que simplemente se sustituyeron con la regulación establecida en el artículo 7, donde se detallan los mismos requisitos formales.

38 Véase supra 3.1. 


\subsection{Forum prorogatum expressum}

El artículo 7 del Reglamentos gemelos, que abre la puerta a la autonomía de las partes para elegir el tribunal competente (prorrogatio fori), sólo entra en juego si falla la aplicación de los artículos 4 y 5 y, por tanto, no es posible la concentración de la jurisdicción. ${ }^{39}$ De acuerdo con el artículo 7 del Reglamento de régimen económico matrimonial, las partes (nótese que se utiliza el término "partes" y no "cónyuges") pueden acordar que la competencia exclusiva para resolver las cuestiones relativas a su régimen económico matrimonial se atribuya a: i) los tribunales del Estado miembro de la lex causae (en virtud de los artículos 22 y 26, apartado 1, las letras a) o b), del Reglamento de régimen económico matrimonial o de los artículos 22 y 26, apartado 1, del Reglamento sobre los efectos patrimoniales de las uniones registradas) o ii) los tribunales del Estado miembro del locus celebrationis. La elección entre las diferentes causas lex se despliega en cuatro posibles opciones en función de las residencias habituales y las nacionalidades de los cónyuges en el momento de la celebración del acuerdo sobre la elección de la ley, lo que supone cinco posibles opciones de conexión judicial para las partes, que se incrementan cuando un cónyuge tiene doble o múltiple nacionalidad.

Estas opciones limitadas son el resultado del equilibrio entre la autonomía de las partes y la seguridad jurídica (especialmente la previsibilidad). ${ }^{40}$ Estas opciones se ven además limitadas por el hecho de que las partes sólo pueden elegir los tribunales de un Estado miembro participante. Si las partes están casadas en un tercer Estado (o en un Estado miembro no participante) o eligen la ley de dicho Estado como aplicable a sus bienes matrimoniales, un acuerdo a favor de los tribunales de dicho tercer Estado no sería válido en virtud del Reglamento sobre los bienes matrimoniales y se aplicarían las normas por defecto del artículo $6 .{ }^{41}$ Por otra parte, un acuerdo válido de prórroga de la competencia de los órganos jurisdiccionales de un determinado Estado miembro en virtud del artículo 7, deroga la competencia de los órganos jurisdiccionales de cualquier otro Estado miembro basándose en los motivos del artículo 6 .

Uno de los cónyuges, de doble nacionalidad croata y bosnia y herzegovina, residente en Eslovenia, y el otro, de nacionalidad alemana y polaca, residente en Luxemburgo, que registraron su pareja en España, poseen propiedades en Croacia, Francia, Alemania y Luxemburgo. Tienen la intención de elegir el tribunal que será competente para pronunciarse sobre las consecuencias patrimoniales de su unión registrada. Sus opciones son las siguientes: (1) los tribunales eslovenos como forum residentiae habitualis para uno de los miembros de la pareja (2) los tribunales luxemburgueses como forum residentiae habitualis para el otro miembro de la pareja, (3) los tribunales croatas como forum nationalis para uno de los miembros de la pareja, (4) los tribunales alemanes como forum nationalis para el otro miembro de la pareja, o (5) los tribunales españoles como forum celebrationis. La nacionalidad bosnia y herzegovina de uno de los socios y la nacionalidad

39 Véase E. Lein, 'Article 7. Election de for', in A. Bonomi and P. Wautelet (eds.), Le droit européen des relations patrimoniales de couple: Commentaire des Règlements nos 2016/1103 et 2016/1104, Bruylant, Bruxelles 2021, p. 433.

40 Ibid., pp. 430-431.

41 Véase P. Franzina, 'Article 7. Choice of Court', in I. Viarengo and P. Franzina (eds.), supra n. 2. 
polaca del otro son irrelevantes, ya que el primer país no es un Estado miembro, mientras que el segundo no es un Estado miembro participante. Los tribunales franceses tampoco están en la lista de tribunales disponibles, ya que la ubicación de los bienes no es un factor relevante para la elección de los tribunales.

Es importante tener en cuenta que los Reglamentos gemelos se refiere a la elección de "los tribunales del Estado miembro" y no a la elección de un tribunal concreto en el Estado miembro elegido. Si un acuerdo incluye la indicación de un tribunal concreto, esto requeriría una interpretación. Es probable que, en tal caso, los tribunales consideren que las partes acordaron los tribunales del Estado miembro al que pertenece el tribunal indicado, mientras que la validez de la elección del lugar (tribunal indicado) se decidiría en función de las normas nacionales del Estado miembro en cuestión.

Podría plantearse la cuestión de quién debe o puede celebrar un acuerdo en virtud del artículo 7. La propia disposición y el considerando 36 utilizan los términos "partes" y "partes interesadas", respectivamente. Mankowski afirma que un tercero puede ser parte de un acuerdo de este tipo, dado que algunos litigios matrimoniales pueden implicar a partes distintas de los cónyuges. ${ }^{42} \mathrm{El}$ término "partes" apunta a una solución flexible que, según Firmston, depende de la naturaleza y el alcance del procedimiento. ${ }^{43}$ Por ejemplo, los "interesados" pueden ser los herederos por ministerio de la ley y los posibles herederos legales identificados en un testamento, así como otras partes que reclaman un determinado derecho a la herencia, como los beneficiarios de un legado o un albacea (pero no los acreedores que sólo tienen un derecho contra la herencia). ${ }^{44}$

El apartado 2 del artículo 7 en ambos Reglamentos (gemelos) regula la forma del acuerdo de elección de foro y exige que "se exprese por escrito y esté fechado y firmado por las partes". Una comunicación por medios electrónicos se considera por escrito si proporciona un registro duradero del acuerdo. ${ }^{45}$ Estos requisitos estrictos en cuanto a la forma, como señala Franzina, garantizan que la voluntad de las partes pueda establecerse con suficiente certeza, basándose en las pruebas adecuadas, además, también sirve para reforzar la elección informada de las partes y la ordenación bien pensada de sus intereses. ${ }^{46}$

La redacción del artículo 7, apartado 3, del Reglamento sobre el régimen económico matrimonial indica que no existen restricciones en cuanto al momento en que se celebra el acuerdo, lo que permite que las partes celebren dicho acuerdo antes, en el momento o después de la celebración del matrimonio en forma de cláusula en el acuerdo prenupcial o el acuerdo sobre el régimen económico matrimonial o en un acuerdo independiente, pero también antes, en el momento o después del inicio del procedimiento judicial. ${ }^{47}$

42 P. Mankowski, 'Internationale Zuständigkeit nach EuGüVO und EuPartVO', in A. Dutta and J. Weber (eds.), supra n. 12 , p. 22.

43 R. Frimston, 'Article 7: Choice of Court' in U. Bergquist, D. Damascelli, R. Frimston, P. Lagarde and B. Reinhartz, supra n. 15, p. 63.

44 Ibid., p. 64.

45 Cabe preguntarse cómo, en el caso del intercambio de correos electrónicos, puede cumplirse el requisito de la firma. Parece natural que se acepte la firma electrónica, sin embargo, lo más probable es que si un acuerdo se firma, se escanea y se envía por correo electrónico, dicho intercambio debería bastar para que un acuerdo cumpla los requisitos del apartado 2 del artículo 7.

46 P. Franzina, 'Article 7. Choice of Court' in I. Viarengo and P. Franzina (eds.), supra n. 2, p, 90.

47 Si se celebra un acuerdo con bastante antelación a estos acontecimientos, los cónyuges no tienen la certeza de que su acuerdo de elección de foro se aplique porque no hay certeza de que el asunto matrimonial se tramite al mismo 


\subsection{Forum prorogatum tacitum}

Los órganos jurisdiccionales de un Estado miembro que, de otro modo, no son competentes en virtud de un acuerdo explícito o de disposiciones de incumplimiento, también pueden ser competentes en virtud del acuerdo tácito de las partes (prorrogatio tacita). ${ }^{48}$ Así, se exige que el demandado comparezca ante un tribunal del Estado miembro que conoce del asunto matrimonial, sin impugnar la competencia del tribunal. Sin embargo, los Reglamentos gemelos añaden un requisito adicional destinado a promover el principio de proximidad, así como la convergencia del forum y el ius: ${ }^{49}$ (i) sólo el órgano jurisdiccional del Estado miembro de la lex causae [en virtud de los artículos 22 y 26, apartado 1, las letras a) o b), del Reglamento sobre los bienes matrimoniales o de los artículos 22 y 26, apartado 1, del Reglamento sobre las consecuencias patrimoniales de las uniones registradas] o (ii) los órganos jurisdiccionales del Estado miembro del locus celebrationis pueden adquirir competencia de esta manera.

Siguiendo el modelo del artículo 26, apartado 2, del Reglamento de Bruselas I bis, que trata de la posición de las partes más débiles (como los consumidores o los trabajadores), el artículo 8 establece que, antes de asumir la competencia, el tribunal debe "asegurarse de que el demandado sea informado de su derecho a impugnar la competencia y de las consecuencias de comparecer o no comparecer". Esta disposición intenta garantizar que la aceptación del demandado no se derive de la falta de información sobre su situación procesal. El consentimiento informado debe darse con independencia de que el demandado esté representado por un abogado o vuelva a recibir asesoramiento jurídico cualificado. ${ }^{50} \mathrm{El}$ momento adecuado para recibir la información no se define en los Reglamentos gemelos, pero lógicamente tiene que ser anterior al momento en que el tribunal establece su jurisdicción, idealmente en el momento en que el demandado es notificado con los documentos que inician el procedimiento, si es posible. ${ }^{51}$

\subsection{Las normas por defecto}

A falta de un acuerdo válido sobre la elección del tribunal en "otros casos" con arreglo al artículo 7 o de una sumisión tácita a la competencia de determinados tribunales con arreglo al artículo 8, entra en juego el artículo 6. Prevé una cascada de motivos de competencia que se desarrollan en torno a la residencia habitual y la nacionalidad. Como se indica en el considerando 35 de los Reglamentos gemelos, estos criterios de vinculación se establecen para garantizar la existencia de un vínculo real entre los cónyuges y el Estado miembro en el que se ejerce la competencia.

tiempo que el procedimiento de sucesión de uno de ellos, o su divorcio, nulidad matrimonial o separación legal. Véase A. Limantė and N. Pogorelčnik Vogrinc, supra n. 9, 135, 146.

48 Las disposiciones que requieren el consentimiento del demandado en algunos asuntos sobre el patrimonio matrimonial que pueden encontrarse en las leyes nacionales, como el artículo 59, apartado 2, de la antigua Ley croata de disolución de normas nacionales con las leyes de otros países en determinadas relaciones económicas (Zakon o rješavanju sukoba zakona s propisima drugih zemalja u određenim odnosima), NN 53/91 y 88/01.

49 S. Corneloup, 'Article 8. Jurisdiction based on the Appearance of the Defendant', in I. Viarengo and P. Franzina (eds.), supra n. 2, pp. 93 and 96.

50 P. Mankowski, 'Internationale Zuständigkeit nach EuGüVO und EuPartVO', in A. Dutta and J. Weber (eds.), supra n. 12, p. 31.

51 E. Lein, 'Article 8. Compétence fondée sur la comparution de défendeur' in A. Bonomi and P. Wautelet (eds.), supra n. 38, p. 455. 
En particular, la jurisdicción en virtud del artículo 6 se atribuye a los tribunales de un Estado miembro en el siguiente orden jerárquico (puede utilizarse el siguiente criterio de jurisdicción siempre que no se cumplan los requisitos de uno anterior): (i) en cuyo territorio los cónyuges tengan su residencia habitual en el momento en que se acuda al tribunal (forum residentiae habitualis communis), ${ }^{52}$ (ii) en cuyo territorio hayan tenido los cónyuges su última residencia habitual, siempre que uno de ellos siga residiendo en él en el momento en que se presente ante el tribunal, (iii) en cuyo territorio el demandado tenga su residencia habitual en el momento en que se le presente la demanda (principio actor sequitur forum rei), y (iv) de la nacionalidad común de los cónyuges en el momento en que se le presente la demanda (forum nationalis communis). Además de los motivos jurisdiccionales anteriores, el artículo 6 del Reglamento sobre los efectos patrimoniales de las uniones registradas añade el quinto paso: (v) la competencia de los tribunales del Estado miembro bajo cuya ley se creó la unión registrada (forum celebrationis). Este motivo adicional se debe al hecho de que no todos los Estados miembros reconocen las uniones registradas, por lo que la atribución de la competencia a los tribunales del Estado en el que se registró la unión garantiza que, al menos en ese Estado miembro, se reconozca la unión y, por tanto, sea posible extinguirla.

Dos eslovenos se conocieron y se casaron en Ámsterdam, donde ambos estudiaron. Posteriormente, el marido se trasladó a Francia en busca de un mejor empleo con la intención de avanzar en su carrera. La esposa también abandonó los Países Bajos, ya que empezó a trabajar en Bruselas, donde espera quedarse. Un año más tarde, la esposa inició el procedimiento de divorcio ante un tribunal belga, que es competente en virtud del artículo 3, apartado 1, letra a), quinto guión, del Reglamento Bruselas II bis. Para que el tribunal belga sea competente para pronunciarse sobre la disolución del patrimonio matrimonial de los cónyuges, es necesario el consentimiento del marido. Si el marido no da su consentimiento, la competencia debe establecerse en virtud del artículo 6 del Reglamento sobre los bienes matrimoniales. Lo primero que hay que comprobar es si los cónyuges tienen una residencia habitual común. En el caso que nos ocupa, no tienen una residencia habitual común, ya que uno vive en Bélgica y el otro en Francia, con la intención de quedarse allí. El siguiente motivo de competencia tampoco da lugar a la competencia, ya que ninguno de los cónyuges reside ya en los Países Bajos. En la tercera escala, sólo los tribunales franceses (si el marido, como demandado, tiene su residencia habitual allí) o, si esto falla, en la última escala, los tribunales eslovenos (por la nacionalidad común de los cónyuges) serían competentes para decidir sobre la propiedad matrimonial de los cónyuges.

Si bien la definición de "residencia habitual" no figura en los Reglamentos gemelos, ni en otra regulación sobre la materia de la UE, ${ }^{53}$ lo más probable es que se interprete en la misma línea que el concepto de residencia habitual del Reglamento Bruselas II bis. ${ }^{54}$

52 El requisito de residencia habitual en un Estado miembro sólo se refiere al mismo país de residencia, lo que significa que no es necesario que los cónyuges (parejas) vivan realmente juntos para que se cumpla este requisito.

53 Las únicas definiciones de "residencia habitual" se refieren a la de las personas jurídicas y físicas que actúan en el ejercicio de su actividad en el artículo 19 del Reglamento Roma I.

54 Véase R. Frimston, 'Article 6: Jurisdiction in Other Cases' in U. Bergquist, D. Damascelli, R. Frimston, P. Lagarde and B. Reinhartz, SUPRA N. 15, pp. 60-61; T. Kruger, 'Finding a Habitual Residence' in I. Viarengo and F.C. Villata (eds.), supra n. 1, pp. 117-132. 
En el derecho internacional privado de la UE, el término "residencia habitual" tiene una interpretación autónoma y sus elementos se detallan en la jurisprudencia del TJUE. ${ }^{55}$ Para que se establezca una residencia habitual, es esencial la presencia física en un Estado miembro, y debe quedar claro que la presencia no es en modo alguno temporal o intermitente. ${ }^{56}$ Aunque la estabilidad y la presencia son importantes, la intención de una persona de establecer una residencia habitual también es relevante, especialmente en los casos en los que la residencia es de un tiempo relativamente corto, siempre que se manifieste mediante ciertas medidas tangibles. ${ }^{57}$ En cualquier caso, el concepto de residencia habitual debe establecerse caso por caso teniendo en cuenta los hechos particulares de cada caso.

En cuanto al último motivo jurisdiccional, es importante subrayar que sólo importa la nacionalidad común de los cónyuges. Si los cónyuges tienen nacionalidades diferentes, este motivo jurisdiccional fracasaría de inmediato. Sin embargo, si los cónyuges comparten más de una nacionalidad común, se ha planteado la cuestión de si la sentencia Hadadi puede aplicarse por analogía. Invocando el considerando 50 del Reglamento sobre el régimen económico matrimonial y el considerando 49 del Reglamento sobre las consecuencias patrimoniales de las uniones registradas, Franzina sostiene que, lamentablemente, se ha excluido explícitamente la opción de recurrir al principio Hadadi ${ }^{58}$ No está claro cómo puede extenderse esta conclusión a la jurisdicción, ya que estos considerandos se sitúan claramente en el contexto de la ley aplicable únicamente, no de la jurisdicción. ${ }^{59}$ Esta política es lógica para la ley aplicable, ya que no puede haber más de una ley aplicable al mismo tiempo. Por el contrario, los tribunales con competencia electiva concurrente son comunes en el derecho internacional privado de la UE y el TJUE en Hadadi consideró que este resultado era aceptable. En su sentencia en el asunto $\mathrm{Ha}$ dadi, el TJUE rechazó el concepto de "nacionalidad efectiva" existente en el Derecho internacional privado de muchos Estados miembros, preocupándose por el hecho de que la comprobación de la competencia esté sujeta a criterios ambiguos y se convierta en algo oneroso, lo que en términos prácticos se traduciría en un litigio potencialmente feroz ya en la fase de determinación de la jurisdicción. ${ }^{60}$ Por estas razones, se afirma que, en lo

55 Hasta ahora, en el contexto del Derecho internacional privado de familia, la mayoría de los asuntos se refieren a la residencia habitual del menor. Véase, por ejemplo, asunto C-523/07, A., EU:C:2009:225, párrafos 34-35; asunto C-497/10 PPU, Mercredi, EU:C:2010:829, párrafos 45-46. Sin embargo, el asunto C-501/20, M.P.A., se refiere a la interpretación de la residencia habitual de adultos que frecuentemente se mueven en el ámbito de la competencia judiciale (diplomáticos), que se encuentra actualmente pendiente ante el TJUE.

56 Asunto C-376/14 PPU, C., EU:C:2014:2268, parafo 51; asunto C-499/15, W. y V., EU:C:2017:118, párrafo 60; asunto C-111/17 PPU, O.L. v P.Q., EU:C:2017:436, párrafo 43; asunto C-512/17, H.R., EU:C:2018:513, párrafo 41; y asunto C-393/18, UD $v$ XB, EU:C:2018:835, párrafo 50 .

57 Asunto C-497/10 PPU Mercredi, EU:C:2010:829, párrafos 50-51.

58 P. Franzina, 'Article 6. Jurisdiction in Other Cases' in I. Viarengo and P. Franzina (eds.), The EU Regulations on the Property Regimes of International Couples. A Commentary, Edward Elgar, Cheltenham 2020, pp. 82-84. Estos considerandos establecen que la cuestión de las nacionalidades múltiples queda fuera del ámbito de aplicación del Reglamento y debe ser resuelta por la legislación nacional, los convenios internacionales aplicables y los principios generales de la legislación de la UE.

59 Esto se desprende de la estructura del preámbulo, que en el caso del Reglamento de régimen económico matrimonial contiene directrices sobre la competencia y las cuestiones de procedimiento en general hasta el considerando 41, mientras que las cuestiones relativas a la ley aplicable se tratan en el considerando 43 y siguientes. Además, la última frase del considerando 50 del Reglamento de régimen económico matrimonial se refiere también a la ley aplicable. Esta estructura se reproduce en el Reglamento sobre las consecuencias patrimoniales de las uniones registradas, con una numeración ligeramente diferente.

60 Véase asunto C-168/08, Hadadi, EU:C:2009:474, párrafo 55. 
que respecta a la competencia en virtud del artículo 6 de los Reglamentos gemelos, el principio Hadadi debería informar a los tribunales a la hora de interpretar la nacionalidad común de los cónyuges como motivo de competencia y sus nacionalidades comunes dobles, triples, etc. deberían considerarse iguales. ${ }^{61}$ Por lo tanto, los tribunales de los dos (o más) Estados miembros de los que los cónyuges son nacionales com-ponentes serían competentes, correspondiendo la elección a la parte que instiga el procedimiento. ${ }^{62}$ Así, cuando se presentan procedimientos paralelos ante los tribunales de diferentes Estados miembros, se puede recurrir al artículo 17 de los Reglamentos gemelos para resolver un conflicto entre estas jurisdicciones concurrentes. ${ }^{63}$

\section{OTRAS NORMAS DE JURISDICCIÓN}

Las principales normas jurisdiccionales mencionadas anteriormente se complementan con el conjunto de otras normas destinadas a tratar situaciones particulares imaginables en los casos matrimoniales transfronterizos. La competencia alternativa, subsidiaria y necesaria puede ser importante para garantizar el acceso a la justicia o su correcta administración. Al ofrecer dos opciones distintas para declinar la competencia, los Reglamentos gemelos garantizan además la protección de los sistemas jurídicos familiares nacionales o la coordinación con terceros países.

\subsection{El forum alternativum}

El artículo 9 del Reglamento sobre el régimen económico matrimonial establece normas de competencia alternativa, que se aplican de forma excepcional, si un tribunal del Estado miembro que es competente en virtud de los artículos 4, 6, 7 o 8, pero considera que, "en virtud de su Derecho internacional privado, el matrimonio en cuestión no está reconocido a efectos del procedimiento de régimen económico matrimonial”. Del mismo modo, el artículo 9 del Reglamento sobre las consecuencias patrimoniales de las uniones registradas establece tales normas si un tribunal del Estado miembro que es competente en virtud de los artículos 4, 5 o 6, letras a), b), c) o d), considera que "su legislación no prevé la institución de la unión registrada”. En tales situaciones, el tribunal puede (pero no es necesario) declinar su competencia. Sin embargo, este artículo no es aplicable si el matrimonio ha terminado en divorcio, separación legal o anulación o cuando las partes han obtenido una disolución o anulación de una unión registrada, según sea el caso, que pueda ser reconocida en el Estado miembro del foro.

Las razones de esta disposición única en el Derecho internacional privado de la UE para ofrecer una "estrategia de salida" por la que los tribunales de los Estados miembros participantes cuyas legislaciones nacionales no pueden reconocer determinados matrimonios, como los matrimonios entre personas del mismo sexo, pueden "retirarse

61 Véase también S. Marino, I rapporti matrimoniali della famiglia nella operazione giudiziaria civile dell' Unione europea, Giuffrè Francis Lefebvre, Milano 2019, 143.

62 Asunto C-168/08, Hadadi, EU:C:2009:474, párrafo 58.

63 A. Bonomi, 'Article 6. Compétence dans des affaires de divorce, de séparation de corps ou d'annulation du mariage' in A. Bonomi and P. Wautelet (eds.), SUPRA N. 38, p. 427. 
elegantemente de la función que se les confiere". ${ }^{64}$ De este modo, los Estados miembros participantes se salvan de perder la competencia sobre el reconocimiento de una relación de pareja, cuando un determinado tipo de relación no se conoce en ese ordenamiento jurídico. ${ }^{65}$ De hecho, las leyes de algunos Estados miembros no contemplan los matrimonios entre personas del mismo sexo, pero sí las uniones registradas de parejas del mismo sexo, mientras que otros no contemplan ninguna de las dos. ${ }^{66}$

Si el órgano jurisdiccional competente para resolver el asunto en virtud del Reglamento respectivo decide declinar su competencia de conformidad con el artículo 9, debe hacerlo sin demora indebida para que la pareja pueda buscar otro foro (forum alternativum). Para evitar las situaciones en las que estas parejas se queden sin acceso a los tribunales como consecuencia de la declinación de la competencia, ${ }^{67}$ las partes pueden acordar atribuir la competencia a los tribunales de cualquier otro Estado miembro participante de conformidad con el artículo 7. En caso de que no se haya alcanzado tal acuerdo, la competencia corresponde a los tribunales de cualquier otro Estado miembro participante de conformidad con el artículo 6 o 8, o a los tribunales del Estado miembro de celebración del matrimonio. El considerando 38 del Reglamento sobre el régimen económico matrimonial y el considerando 36 del Reglamento sobre las consecuencias patrimoniales de las uniones registradas aclaran que la jerarquía entre los criterios de competencia que, por lo demás, existe en estas disposiciones (artículos 6 y 8) no se aplica cuando se recurre a cualquiera de ellos como forum alternativum.

\subsection{Limitación de los procedimientos}

Además de la opción del artículo 9 del Reglamento de los gemelos, el artículo 13 prevé la posibilidad de que el tribunal decline parcialmente su competencia, sin embargo, sólo con respecto a los bienes individuales. La razón que subyace a esta opción es la coordinación con la jurisdicción de los terceros estados. A falta de un régimen general de coordinación de las situaciones que implican una conexión con un tercer Estado como en el Reglamento Bruselas I bis, esta opción tiene por objeto proteger los intereses de las partes cuando existe un tipo específico de conexión con un tercer Estado. Funcionando como una excepción, esta disposición perfora el principio de la unidad de bienes que, ${ }^{68}$ además de estar redactado con respecto a la ley aplicable, es también un elemento estructural en la arquitectura de las normas jurisdiccionales.

Dicha limitación del alcance del procedimiento está a disposición del tribunal que conoce del régimen económico matrimonial cuando (i) el patrimonio del causante, cuya sucesión entra en el ámbito de aplicación del Reglamento de sucesiones, comprende bienes situados en un tercer Estado, (ii) una de las partes ha solicitado la limitación del procedimiento, y (iii) cabe esperar que la decisión de este tribunal respecto de uno o varios de

64 I. Kunda, supra n. 9, 27, 34.

65 P. Franzina, 'Article 9. Alternative Jurisdiction' in I. Viarengo and P. Franzina (eds.), The EU Regulations on the Property Regimes of International Couples. A Commentary, Edward Elgar, Cheltenham 2020, p. 108.

66 Para una visión completa del tipo de relaciones de pareja reconocidas en los distintos Estados miembros, véase L. Ruggeri, I. Kunda and S. Winkler (eds.), Family Property and Succession in EU Member States National Reports on the Collected Data, University of Rijeka, Faculty of Law, Rijeka 2019.

67 P. Franzina, supra n. 12, 159, 185.

68 Véase el capítulo 5 de este volumen. 
dichos bienes no sea reconocida y, en su caso, declarada ejecutiva en ese tercer Estado. El parecido con el artículo 12 del Reglamento de sucesiones no es en absoluto accidental; las dos disposiciones están funcionalmente relacionadas porque las cuestiones de los bienes matrimoniales son a menudo previas a las del procedimiento de sucesión. Por lo tanto, las condiciones equivalentes contenidas en las disposiciones permiten resultados combinados y coherentes cuando el mismo bien situado en un tercer Estado es objeto de ambos tipos de cuestiones. Dicho esto, los resultados de la aplicación de las dos disposiciones no tienen por qué ser los mismos en todos los casos, ya que los tribunales de diferentes Estados miembros pueden ser competentes en los procedimientos separados, uno sobre una cuestión matrimonial y el otro sobre una cuestión de sucesión. Además, las decisiones sobre la prescripción de los dos procedimientos son formalmente distintas y puede darse el caso de que las condiciones no se cumplan respecto a un asunto pero sí respecto al otro. ${ }^{69}$

El tercer requisito parece ser el tema central para el tribunal al que se le presenta el caso. Implica la evaluación de la situación hipotética en la que se dictaría la resolución del tribunal al que se ha acudido y se intentaría reconocer (y ejecutar) en el tercer Estado en el que se encuentran los bienes. Dicha evaluación debe realizarse teniendo en cuenta los elementos de hecho y de derecho del caso ante el tribunal al que se ha presentado la demanda y las normas sobre reconocimiento (y ejecución) en el tercer Estado en cuestión. El tercer requisito se cumplirá cuando el tribunal ante el que se ha presentado la demanda considere que su posible decisión no sería reconocida en el tercer estado, por ejemplo, porque dicha cuestión es de competencia exclusiva de los tribunales del tercer estado. ${ }^{70}$

La discrecionalidad del tribunal para limitar el procedimiento en virtud de los Reglamentos gemelos no afecta al derecho de las partes en virtud de la lex fori a limitar el alcance del procedimiento.

\subsection{Forum subsidiarium}

El recurso a las normas nacionales sobre jurisdicción internacional se permite en virtud del artículo 10 sobre jurisdicción subsidiaria (forum subsidiarium), inspirado en el apartado 2 del artículo 10 del Reglamento sobre sucesiones. ${ }^{71}$ Esta vía está disponible bajo condiciones muy estrictas: (i) ningún órgano jurisdiccional de un Estado miembro es competente en virtud de los artículos 4, 5, 6, 7 o 8, o todos los órganos jurisdiccionales del artículo 9 han declinado su competencia y ningún órgano jurisdiccional es competente en virtud del apartado 2 del artículo 9, y (ii) los bienes inmuebles de uno o de ambos cónyuges se encuentran en el territorio del Estado miembro del foro.

Las parejas registradas son nacionales de Noruega y Estados Unidos, respectivamente. Concluyeron su relación de pareja en 2007 en Noruega y viven en Lituania desde 2013. Son propietarios de varios inmuebles en distintos países. Uno de ellos está registrado como propietario de un apartamento en un pueblo costero español. En 2020, lo vende a un tercero. Para intentar invalidar este contrato, el otro socio

69 A. Bonomi, 'Article 13. Limitation de la procédure' in A. Bonomi and P. Wautelet (eds.), supra n. 38, p. 507.

70 Véase ibid., p. 513 (mencionando los sistemas de Common Law); P. Franzina, 'Article 13. Limitation of Proceedings' in I. Viarengo and P. Franzina (eds.), supra n. 2, p. 134 (mencionando la ley tunecina).

71 Véase también la disposición sobre la competencia subsidiaria en el artículo 6 del Reglamento sobre alimentos. 
inicia el procedimiento en España solicitando al tribunal que también dicte una sentencia declarativa que establezca que son copropietarios del apartamento. ¿Son los tribunales españoles competentes para conocer de la acción declarativa? Dado que este caso no está relacionado con la sucesión de un socio registrado ni con la disolución de la pareja registrada, los artículos 4 y 5 son inaplicables. Lo mismo ocurre con los artículos 7 y 8 , ya que los socios no han acordado ni expresa ni tácitamente la competencia de ningún tribunal, así como con el artículo 6, dado que los socios tienen su residencia habitual en Lituania (que es un Estado miembro no participante), nunca han residido habitualmente en ninguno de los Estados miembros participantes, no tienen una nacionalidad común y su unión registrada se creó con arreglo a la legislación noruega (que es un Estado no miembro). El artículo 9 no se cuestiona en este caso, ya que no es posible la declinación de la competencia, puesto que ningún tribunal de un Estado miembro participante es competente. En consecuencia, la respuesta a la pregunta sobre la competencia del tribunal español es afirmativa porque el bien inmueble (supuestamente) propiedad de al menos uno de los socios registrados se encuentra en España.

El alcance de la jurisdicción así establecida se limita únicamente a los bienes inmuebles situados en ese Estado miembro, presentando así el otro punto en el que se traspasa el principio de la unidad de bienes cuando se trata de normas jurisdiccionales. ${ }^{72}$ En virtud del principio de territorialidad, si hay más bienes de este tipo situados en dos o más Estados miembros participantes, los tribunales de cada uno de esos Estados son competentes para resolver únicamente la cuestión relacionada con el bien inmueble en el Estado del foro. Sin embargo, las opiniones de los expertos parecen diferir en cuanto a la noción de "inmueble". Mientras que algunos abogan por la aplicabilidad de la lex rei sitae para determinar el carácter mueble o inmueble del bien, ${ }^{73}$ otros tienden a favorecer la interpretación euroautonómica por referencia a la misma noción en otros ámbitos del Derecho de la UE. ${ }^{74}$

\subsection{Forum necessitatis}

Haciéndose eco de otros reglamentos de la UE, ${ }^{75}$ el artículo 11 de los Reglamentos gemelos prevé el forum necessitatis como último recurso y con carácter excepcional por debilitar los principios de proximidad y seguridad jurídica (especialmente la previsibilidad). Para establecer la competencia por este motivo, deben cumplirse los siguientes requisitos: (i) ningún órgano jurisdiccional de un Estado miembro es competente en virtud de los artículos 4, 5, 6, 7, 8 o 10, o todos los órganos jurisdiccionales en virtud del artículo 9 han declinado su competencia y ningún órgano jurisdiccional de un Estado miembro es competente en virtud del apartado 2 del artículo 9 o del artículo 10, (ii) el procedimiento en materia matrimonial no puede iniciarse o tramitarse razonablemente o sería imposible

72 Otro caso de este tipo se refiere al artículo 13. Véase el apartado 4.2.

73 P. Mankowski, 'Internationale Zuständigkeit nach EuGüVO und EuPartVO' in A. Dutta and J. Weber (eds.), SUPRA N. 12, p. 40; A. Bonomi, 'Article 13. Limitation de la procédure' in A. Bonomi and P. Wautelet (eds.), supra n. 38, p. 482.

74 P. Franzina, ‘Article 10. Subsidiary Jurisdiction' in I. Viarengo and P. Franzina (eds.), supra n. 2, p. 113.

75 Véase, por ejemplo, el artículo 7 del Reglamento sobre alimentos y el artículo 11 del Reglamento sobre sucesiones. 
en un tercer Estado con el que el asunto esté estrechamente relacionado, y (iii) el asunto tiene una conexión suficiente con el Estado miembro del foro.

Mientras que el primer requisito es deducible siguiendo paso a paso las provi-siones a las que se refiere, los segundos requisitos pueden suponer una dificultad considerable para el tribunal que se ocupa del asunto matrimonial. El considerando 41 del Reglamento sobre el régimen económico matrimonial y el considerando 40 del Reglamento sobre las consecuencias patrimoniales de las uniones registradas explican que dicha imposibilidad puede existir en una situación de guerra civil en un tercer Estado, o cuando no se puede esperar razonablemente que un cónyuge inicie o lleve a cabo un procedimiento en dicho Estado. La primera pertenece a las situaciones de imposibilidad absoluta porque el poder judicial ha dejado de funcionar debido a las circunstancias de la guerra $u$ otras circunstancias, incluidas las catástrofes naturales o el estado de epidemia peligrosa, o por la falta de motivos en los que pueda basarse la jurisdicción en el caso en cuestión. La imposibilidad relativa está presente en situaciones como las normas procesales gravemente deficientes que exponen a las partes a un trato discriminatorio. ${ }^{76}$ Asimismo, la imposibilidad existiría cuando el tercer Estado no reconociera ni los matrimonios entre personas del mismo sexo ni las consecuencias patrimoniales de los mismos. ${ }^{77}$

Aunque el tercer requisito se ha identificado como difícil de interpretar, es común que debe evaluarse a la luz de las circunstancias particulares de cada caso. Los posibles elementos de conexión son cualquiera de los factores de conexión mencionados en las demás disposiciones de los Reglamentos gemelos, cuando no den lugar a la competencia de los tribunales de cualquiera de los Estados miembros participantes en virtud de cualquiera de las disposiciones de atribución de competencia anteriormente tratadas. ${ }^{78}$

\subsection{Foro de reconvenciones}

En el artículo 12 de los Reglamentos gemelos se ha incluido una norma bien establecida en el Derecho internacional privado de la UE, ${ }^{79}$ según la cual el tribunal en el que esté pendiente el procedimiento en virtud de cualquiera de los artículos $(4,5,6,7,8,9(2), 10 \mathrm{u}$ 11) también es competente para pronunciarse sobre una reconvención. ${ }^{80}$ La reconvención es admisible siempre que entre en el ámbito de aplicación ratione materiae del respectivo Reglamento, ${ }^{81}$ lo que significa que debe referirse al patrimonio matrimonial o a una consecuencia patrimonial de la unión registrada. También debe estar dentro del ámbito de aplicación ratione temporis de los Reglamentos. En los comentarios se ha afirmado que la demanda reconvencional también debe entrar en el ámbito de la jurisdicción del tribu-

76 A. Bonomi, 'Article 11. Forum necessitatis' in A. Bonomi and P. Wautelet (eds.), supra n. 38, pp. 492-493.

77 Véase I. Viarengo, 'Effetti patrimoniali delle unioni civili transfrontaliere e la nuova disciplina europea' (2018) 54 Rivista di diritto internazionale privato e processuale 33, 46; G. Biagioni, 'Article 11. Forum necessitatis' in I. Viarengo and P. Franzina (eds.), supra n. 2, p. 119.

78 A. Bonomi, 'Article 11. Forum necessitatis' in A. Bonomi and P. Wautelet (eds.), supra n. 38, p. 495.

79 Véase, por ejemplo, el apartado 3 del artículo 8 del Reglamento Bruselas I bis y el artículo 4 del Reglamento Bruselas II bis.

80 El concepto de "demanda reconvencional" ha sido interpretado anteriormente por el TJUE en el contexto del Convenio de Bruselas y del Reglamento de Bruselas I, los predecesores del Reglamento de Bruselas I bis. Véase asunto C-341/93, Danvcern Production A/S v Schuhfabriken Otterbeck GmbH \& Co., EU:C:1995:239, párrafo 18; asunto C-185/15, Marjan Kostanjevec v F\&S Leasing, GmbH., EU:C:2016:763, párrafo 32-33.

81 Véase el capítulo 3 de este volumen. 
nal en cuestión. A modo de ejemplo, cuando el tribunal tiene competencia subsidiaria, la reconvención debe referirse al bien inmueble en el Estado miembro del foro. ${ }^{82}$

Aunque la disposición del artículo 12 no especifica más requisitos, los comentarios sugieren que debe verificarse cierta conexión entre la demanda principal y la reconvención. ${ }^{83}$ Sin embargo, esto no parece estar previsto como ningún requisito particular, ya que la conexión parece estar suficientemente garantizada mediante el requisito de que la demanda reconvencional entre en el ámbito de aplicación del Reglamento en cuestión, ya que todo el Reglamento se refiere al mismo tipo de asuntos. Este es también el caso de la disposición sobre demandas de reconvención del artículo 4 del Reglamento Bruselas II bis, que exige igualmente que entre en el ámbito de aplicación de dicho Reglamento. Por el contrario, el Reglamento de Bruselas I bis abarca diversos tipos de asuntos, de ahí que su disposición en el apartado 3 del artículo 8 defina con más detalle los elementos de conexión exigiendo que surja del "mismo contrato o de los mismos hechos en que se basó la demanda inicial".

\subsection{Foro de medidas provisionales}

De manera ya tradicional, ${ }^{84}$ el artículo 19 de los Reglamentos gemelos establece que pueden solicitarse a los tribunales de un Estado miembro las medidas provisionales y cautelares ${ }^{85}$ que pueda disponer la legislación de dicho Estado, incluso si, en virtud del Reglamento respectivo, los tribunales de otro Estado miembro son competentes en cuanto al fondo del asunto. Así pues, los tribunales de cualquier Estado miembro participante que sean competentes en cuanto al fondo en virtud de los Reglamentos gemelos también son directamente competentes para conceder medidas provisionales. Esta es la extensión natural de la competencia del tribunal para decidir sobre el fondo. Además, la competencia provisional para conceder tales medidas se atribuye a los tribunales del Estado miembro participante cuya legislación prevé una medida concreta solicitada. Se trata de una remisión a las normas nacionales, tanto en lo que se refiere al fondo como a la competencia interna relativa a las medidas provisionales. ${ }^{86}$

Una pareja de nacionalidad mixta, francesa y alemana, con residencia habitual en Bruselas, se está divorciando y, como corolario, está resolviendo sus problemas de propiedad matrimonial. Uno de sus valiosos bienes inmuebles se encuentra en Croacia. Con el fin de proteger sus intereses en dicho bien inmueble, la esposa solicita a los tribunales croatas la medida provisional prevista en el Derecho croata, que consiste en la prohibición de venta u otra enajenación del bien inmueble en

82 P. Franzina, SUPRA N. 12, 193; A. Bonomi, 'Article 12. Demandes reconventionnelles' in A. Bonomi and P. Wautelet (eds.), supra n. 38, p. 499, 500-501.

83 P. Mankowski, 'Internationale Zuständigkeit nach EuGüVO und EuPartVO' in A. Dutta and J. Weber (eds.), supra n. 12, p. 43; P. Franzina, supra n. 12, 193.

84 Véase, por ejemplo, el artículo 35 del Reglamento Bruselas I bis, el artículo 20 del Reglamento Bruselas II bis, el artículo 14 del Reglamento sobre alimentos y el artículo 54 del Reglamento de sucesiones.

85 La noción de "medidas provisionales y cautelares" ha sido elaborada en la jurisprudencia del TJUE. En este sentido, véase el asunto C-261/90, Mario Reichert, Hans-Heinz Reichert and Ingeborg Kockler v Dresdner Bank $A G$, EU:C:1992:149, párrafo 31.

86 S. Migliorini, 'Article 19. Mesures provisoires et conservatoires' in A. Bonomi and P. Wautelet (eds.), supra n. 38, p. 556. 
cuestión, así como la inscripción de la prohibición en el Registro de la Propiedad y la atribución temporal de la gestión del bien inmueble a la esposa o a un tercero.

El artículo 19 es una vía práctica para preservar la situación de hecho o de derecho ante los órganos jurisdiccionales del propio Estado miembro en el que habrá de ejecutarse la medida. Su eficacia radica no sólo en la ejecutoriedad directa que evita el exequátur, sino también en el mantenimiento del efecto sorpresa cuando la lex fori lo prevé. ${ }^{87}$

\section{COORDINACIÓN ENTRE LOS PROCEDIMIENTOS DE LOS DISTINTOS ESTADOS MIEMBROS}

Una de las cuestiones importantes relacionadas con la coordinación judicial entre tribunales de diferentes Estados miembros es la relativa a los procedimientos concurrentes. A tal efecto, los Reglamentos gemelos definen normas de prioridad cuando hay procedimientos paralelos o conexos pendientes ante los tribunales de dos o más Estados miembros participantes. Estas normas determinan el orden cronológico en el que los órganos jurisdiccionales ante los que se presenta la demanda deben decidir cada uno de ellos sobre su propia competencia siguiendo el principio prior in tempore, potior in iure. El objetivo es minimizar el riesgo de procedimientos concurrentes, ya que esto puede dar lugar a decisiones contradictorias o irreconciliables y, en consecuencia, obstaculizar la libre circulación de sentencias entre los Estados miembros participantes. Para evitar la separación territorial del espacio judicial europeo es fundamental el respeto del principio de reconocimiento mutuo. Supone la existencia de una confianza mutua entre los Estados miembros, ${ }^{88}$ en los casos de los bienes matrimonial de los Estados miembros participantes. Desde un punto de vista más práctico, para que el sistema de coordinación sea funcional, también era necesario prever normas autónomas sobre el momento en que se considera que un tribunal está sometido a juicio.

\subsection{Sustanciación del asunto ante un órgano jurisdiccional}

Teniendo en cuenta la variedad de soluciones procesales en los distintos Estados miembros y basándose en sus predecesores ${ }^{89}$ el artículo 14 de los Reglamentos gemelos define cuándo se considera que un tribunal ha acudido a él refiriéndose al "escrito de incoación del procedimiento o documento equivalente", o a la "apertura del procedimiento" o al "registro del caso", según el caso. Si el procedimiento es iniciado por las partes, se considera que el tribunal está presente a) en el momento en que se presenta el documento ante el tribunal o b) si el documento debe ser notificado antes de ser presentado ante el tribunal, en el momento en que lo recibe la autoridad responsable de la notificación. Es importante que los trámites posteriores se realicen si son necesarios en virtud de la lex fori. Si el procedimiento se abre de oficio c), se considerará que el tribunal ha acudido

87 L. Sandrini, 'Article 19. Provisional, Including Protective, Measures' in I. Viarengo and P. Franzina (eds.), supra n. 2, p. 173 .

88 K. Lenaerts, 'The Principle of Mutual Recognition in the Area of Freedom, Security and Justice', The Fourth Annual Sir Jeremy Lever Lecture, University of Oxford, 30 January 2015, <www.law.ox.ac.uk $>$ accessed 30.04.2021, p. 4.

89 Véanse, por ejemplo, el artículo 32 del Reglamento Bruselas I bis, el artículo 16 del Reglamento Bruselas II bis, el artículo 9 del Reglamento sobre alimentos y el artículo 14 del Reglamento sobre sucesiones. 
a él en el momento en que adopte la decisión de abrir el procedimiento o, cuando no se requiera tal decisión, en el momento en que el tribunal registre el asunto.

El artículo 16 define las medidas que el órgano jurisdiccional de un Estado miembro participante ante el que se ha interpuesto una demanda debe adoptar si el demandado con residencia habitual en otro Estado no comparece. El objetivo es salvaguardar su derecho a la defensa en virtud del principio audiatur et altera pars. ${ }^{90}$

\subsection{Litispendencia}

El artículo 17 define la litispendencia como la situación en la que un procedimiento con la misma causa y entre las mismas partes se presenta ante tribunales de diferentes Estados miembros. Las nociones de "la misma causa" y de "las mismas partes" han sido dilucidadas en repetidas ocasiones por el TJUE en el marco del Reglamento Bruselas I bis y sus predecesores, basándose en una interpretación autónoma, sistemática y teleológica. En concreto, estas normas tienen por objeto excluir, en la medida de lo posible y desde el principio en el espacio judicial europeo, la posibilidad de que se produzca una situación que dé lugar al no reconocimiento de una resolución en un Estado miembro debido a su irreconciliabilidad con una resolución dictada en un litigio entre las mismas partes en el otro Estado miembro en el que se solicita el reconocimiento. ${ }^{91}$

Según la interpretación autónoma, la noción de "causa de la acción" comprende tanto la "causa de la acción", es decir, los hechos y la norma jurídica invocados como fundamento de la acción, como el "objeto de la acción" (o "materia"), que significa los fines que persigue la acción. ${ }^{92}$ Por lo tanto, la diferente naturaleza de las demandas en virtud del derecho nacional aplicable no es en sí misma un obstáculo para que los procedimientos se consideren la "misma causa de acción". Por ejemplo, el procedimiento para la declaración de nulidad de un acuerdo matrimonial y el procedimiento para la ejecución del mismo acuerdo mediante la separación de bienes se considerarían con la misma causa de acción porque la validez del acuerdo se encuentra en el centro de ambas demandas. ${ }^{93}$ Sin embargo, al pronunciarse sobre la litispendencia en los procedimientos sujetos al Re-

90 Se hace referencia aquí al artículo 19 del Reglamento (CE) no 1393/2007 del Parlamento Europeo y del Consejo, de 13 de noviembre de 2007, relativo a la notificación y al traslado en los Estados miembros de documentos judiciales y extrajudiciales en materia civil o mercantil (notificación y traslado de documentos) y por el que se deroga el Reglamento (CE) n ${ }^{\circ}$ 1348/2000 del Consejo, DO L 324 de 10.12.2007, pp. 79-120, que a partir del 1 de julio de 2022 será sustituido por el Reglamento (UE) 2020/1784 del Parlamento Europeo y del Consejo, de 25 de noviembre de 2020, relativo a la notificación y al traslado en los Estados miembros de documentos judiciales y extrajudiciales en materia civil o mercantil (notificación y traslado de documentos) (refundición), DO L 405 de 2.12.2020, pp. 40-78, o el artículo 15 del Convenio de La Haya de 15 de noviembre de 1965 relativo a la notificación y al traslado en el extranjero de documentos judiciales y extrajudiciales en materia civil o mercantil.

91 Véase, por ejemplo, asunto C-144/86, Gubisch Maschinenfabrik KG v Giulio Palumbo, EU:C:1987:528, párrafos 8 y 11; asunto C-406/92, The owners of the cargo lately laden on board the ship 'Tatry' $v$ the owners of the ship 'Maciej Rataj', EU:C:1994:400, párrafos 30 y 32. On the grounds for refusal of recognition and enforcement see below chapter 6 in this volume.

92 Asunto C-406/92, The owners of the cargo lately laden on board the ship 'Tatry' $v$ the owners of the ship 'Maciej Rataj', EU:C:1994:400, párrafos 38 y 40. Véase también asunto C-144/86, Gubisch Maschinenfabrik KG v Giulio Palumbo, EU:C:1987:528, párrafos 14 et seq.

93 Véase por analogia el asunto C-144/86, Gubisch Maschinenfabrik KG v Giulio Palumbo, EU:C:1987:528, párrafos $16-17$. 
glamento Bruselas II bis, el TJUE sostuvo que no puede existir litispendencia cuando una acción es de medida provisional y la otra acción es de resolución sobre el fondo. ${ }^{94}$

La noción de "las mismas partes" se ha interpretado, no sólo en el sentido de que las partes pueden estar en posiciones procesales inversas, ${ }^{95}$ sino también más allá de su significado literal para significar las partes sobre las que el efecto de res iudicata de la decisión dictada contra una parte se extiende a la otra, siempre que sus intereses sean idénticos e indisociables. ${ }^{96}$ En los Reglamentos gemelos, en particular, la posibilidad de que un tercero participe en el procedimiento se reconoce en las definiciones relacionadas con sus respectivos ámbitos. Así, en la definición del "régimen económico matrimonial" del artículo 3, apartado 1, letra a), del Reglamento sobre el régimen económico matrimonial se hace referencia no sólo a "las relaciones patrimoniales entre los cónyuges" sino también a "sus relaciones con terceros". Esta última referencia se encuentra también en el artículo 3, apartado 1, letra b), del Reglamento sobre las consecuencias patrimoniales de las uniones registradas.

Los pasos que deben dar los dos tribunales en los que los procedimientos están pendientes simultáneamente son los siguientes: cualquier tribunal ante el que se presente una demanda posterior debe suspender de oficio sus procedimientos hasta que se establezca la competencia del tribunal ante el que se presentó la primera demanda. El tribunal ante el que se interpuso la demanda posterior no está en condiciones de verificar o decidir sobre la competencia del tribunal ante el que se interpuso la demanda inicial y siempre tiene que esperar la decisión del tribunal ante el que se interpuso la demanda. ${ }^{97}$ Esta decisión es vinculante para los tribunales de otros Estados miembros. ${ }^{98}$ Son posibles dos escenarios diferentes: uno, si el tribunal al que se acudió en primer lugar se declara competente, el segundo tribunal debe declinar su competencia ex officio sin examinar la decisión del primer tribunal; o el otro, el tribunal al que se acudió en primer lugar se declara incompetente, cuando el tribunal al que se acudió posteriormente puede reanudar su procedimiento (y determinar su competencia). Para facilitar la eficacia de la coordinación entre los procedimientos paralelos, existe la obligación, previa solicitud, de una pronta comunicación entre los órganos jurisdiccionales de los distintos Estados miembros en relación con la fecha en la que se interpuso la demanda.

\subsection{Acciones relacionadas}

El artículo 18 del Reglamento sobre los gemelos define las acciones conexas como las acciones pendientes ante los órganos jurisdiccionales de diferentes Estados miembros que están tan estrechamente vinculadas entre sí que es conveniente conocerlas y resolverlas conjuntamente para evitar el riesgo de que se produzcan decisiones irreconciliables en

94 Asunto C-296/10, Bianca Purrucker v Guillermo Vallés Pérez (Purrucker II), EU:C:2010:665, párrafo 69.

95 Asunto C-144/86, Gubisch Maschinenfabrik KGv Giulio Palumbo, EU:C:1987:528, párrafo 19.

96 Asunto C-351/96, Drouot assurances SA v Consolidated metallurgical industries (CMI industrial sites), Protea assurance and Groupement d'intérêt économique (GIE) Réunion européenne, EU:C:1998:242.

97 Asunto C-351/89, Overseas Union Insurance and Others v New Hampshire Insurance Company, EU:C:1991:279, párrafo 25.

98 Los órganos jurisdiccionales de los demás Estados miembros están vinculados por las decisiones anteriores sobre la competencia del órgano jurisdiccional ante el que se interpuso la primera demanda, incluidas sus conclusiones in obiter. Véase asunto C-456/11, Gothaer Allgemeine Versicherung A G and Others v Samskip GmbH, EU:C:2012:719; I. Kunda and D. Vrbljanac, 'Lis Pendens' in C. Honorati (ed.), Jurisdiction in Matrimonial Matters, Parental Responsibility and International Abduction. A Handbook on the Application of Brussels IIa Regulation in National Courts, Giappichelli and Peter Lang, Torino 2017, p. 219, 232-233. 
procedimientos separados. Migliorini distingue dos elementos en esta definición. ${ }^{99}$ El primero es el elemento sustantivo relativo a la estrecha conexión entre los procedimientos, que se manifiesta en cuestiones comunes que deben ser respondidas en ambos procedimientos. El segundo elemento de la definición es latente porque está relacionado con el riesgo de decisiones irreconciliables, que sólo puede evaluarse imaginando varios escenarios de resultados en los dos procedimientos y comparándolos. La noción de "irreconciliabilidad" debe interpretarse de forma autónoma y en un sentido más amplio cuando se lee en el contexto del artículo 18 (en comparación con el artículo 37 ) ${ }^{100}$ para abarcar las situaciones de riesgo de decisiones conflictivas, incluso si las decisiones pueden ejecutarse por separado y sus consecuencias jurídicas no son mutuamente excluyentes. ${ }^{101}$ La aplicación de esta disposición sólo se pone en marcha a petición de una de las partes.

A diferencia de las situaciones de litispendencia, en las que la actuación de los tribunales está estrictamente prescrita, en las situaciones de dos acciones conexas el tribunal ante el que se interpuso la demanda goza de cierta discrecionalidad para suspender o no sus procedimientos. Esta discreción está limitada por las siguientes consideraciones (1) las acciones relacionadas están pendientes en primera instancia (2) existe la solicitud de una de las partes que pide al tribunal que se inhiba de su jurisdicción y (3) el tribunal ante el que se interpuso la primera demanda es competente para las acciones en cuestión y (4) la ley del tribunal ante el que se interpuso la primera demanda permite la consolidación de las acciones en cuestión.

\section{OBSERVACIONES FINALES}

El análisis anterior de las normas jurisdiccionales del Reglamento de los gemelos demuestra lo que ya se ha señalado anteriormente: sus normas presentan "un notable grado de complejidad". ${ }^{102}$ De este modo, presentan una extensión del enfoque nomotécnico empleado en el Reglamento de sucesiones, mientras que su estructura general sigue otros reglamentos en el ámbito de la cooperación en materia civil. La citada complejidad en la técnica legislativa es evidente tanto en la superficie como en el fondo. En lugar de uno o dos artículos con varias conexiones básicas para asuntos matrimoniales (y asuntos de consecuencias patrimoniales de las uniones registradas), que se encuentran típicamente en el Derecho internacional privado nacional de los Estados miembros, los Reglamentos gemelos introducen una arquitectura de múltiples capas y altamente especializada de las normas ju-risdiccionales. Los principios fundamentales que informan los elementos estructurales del sistema de normas jurisdiccionales, incluida la selección de los motivos jurisdiccionales, consisten en la seguridad jurídica, la previsibilidad, la proximidad, la unidad de activos, así como la convergencia del forum y el ius. En este contexto, las normas (y las excepciones) se configuran de diversas maneras, exponiendo diferentes características, teniendo diversos alcances, enumerando requisitos específicos y situándose en diferentes interrelaciones de estructuras y funciones.

99 S. Magliorini, 'Article 18. Connexité' in A. Bonomi and P. Wautelet (eds.), SUPRA N. 38, p. 549, 551.

100 Véase el capítulo 6 de este volumen.

101 Asunto C-406/92, The owners of the cargo lately laden on board the ship 'Tatry'v the owners of the ship 'Maciej Rataj', EU:C:1994:400, párrafo 55.

102 P. Franzina, supra n. 12, 193. 
Esta complejidad puede dificultar la predicción directa de los tribunales competentes por las partes y desafiar el análisis simple y rápido de la jurisdicción por los tribunales. La aplicación en la práctica del sistema de normas de competencia del Reglamento sobre los gemelos requiere un profundo conocimiento tanto del Derecho internacional privado como del Derecho de la UE, por lo que está reservada principalmente a los especialistas en Derecho. Es poco probable que las partes legas puedan confiar en estas normas sin un asesoramiento jurídico profesional, independientemente de lo mucho que apoye esto la Comisión Europea, como demuestran los fondos asignados a la creación de estas herramientas prácticas y listas para usar en los últimos años. ${ }^{103}$ En particular, la elección de los tribunales, que -aunque limitada- pretende ayudar a organizar las relaciones patrimoniales de las parejas, depende en gran medida de la concienciación de los interesados (en la misma línea que en el Reglamento de sucesiones), pero también de aquellos de los que reciben asesoramiento jurídico. Habrá que desarrollar todo un conjunto de nuevas cláusulas y documentos jurídicos para que las parejas puedan aprovechar al máximo la opción de autonomía de las partes de los Reglamentos gemelos y para que se cumplan las aspiraciones de los legisladores de que la vida cotidiana de los ciudadanos y las familias de la UE que se desplazan sea menos oscura, ya que podrán organizar de antemano sus relaciones patrimoniales familiares.

103 Esto se hace principalmente a través del Programa de Justicia de la UE, mediante el cual la Comisión financia proyectos destinados no sólo a la formación de los profesionales, sino también a acercar las normas a las propias partes. Véase e.g. Personalized Solution in European Family and Succession Law - PSEFS (br. 800821-JUSTAG-2017/JUST-JCOO-AG-2017), < www.euro-family.eu> accessed 31.04.2021. 